\title{
Discrimination of Soil Phases by Dual Energy X-ray Tomography
}

\author{
H. Rogasik,* J. W. Crawford, O. Wendroth, I. M. Young, M. Joschko, and K. Ritz
}

\begin{abstract}
Numerous soil ecological functions are influenced by soil structure through its impact on spatial and temporal distributions of soil particles, water, and air within the soil profile. The nondestructive technique of $x$-ray computed tomography (CT) was used for studying soil structure. $X$-ray attenuation determined for two energy levels $(80 \mathrm{kV}$ and $120 \mathrm{kV}$ ) was used to calculate distributions of water, air, and solids, as well as the voxel dry bulk density for two silt loam subsoils. The spatial resolution during scanning was $0.25 \mathrm{~mm}$ in the horizontal and $1 \mathrm{~mm}$ in the vertical direction. For different voxel sizes, the weighted mean of the derived volumetric water, air, and solid contents, and the dry bulk densities agreed with the sample's phase composition and dry bulk density obtained by weighing. The use of dual energy scanning to study the heterogeneity of soil structure and the spatial distribution of water, air, and solids is discussed.
\end{abstract}

$\mathrm{A}^{\mathrm{v}}$ IMPORTANT LIMITATION IN SOIL SCIENCE is the lack of knowledge concerning the effect of soil structure on functional processes. The application of x-ray computed tomography (CT) provides the possibility for a nondestructive, 3-D morphological characterization of soil structure at the microscale level. X-ray CT measurements have previously been used to obtain nondestructive measurements of water content and dry bulk density (Petrovic et al., 1982; Crestana et al., 1985; Brown et al., 1987; Anderson et al., 1988; Jenssen and Heyerdahl, 1988; Tollner and Ramseur, 1988; Tollner and Verma, 1989; Hopmans et al., 1992, 1994), as well as macroporosity and pore continuity (Grevers et al., 1989; Warner et al., 1989; Anderson et al., 1990; Peyton et al., 1992; Grevers and de Jong, 1994). In addition, CT has been applied to characterize the heterogeneity of soil structure at the microscale level (Phogat et al., 1991; Rogasik et al., 1994; Heijs et al., 1995, 1996) and to investigate the fractal properties of soil structure (Peyton et al., 1994).

Based on single energy-level scanning, it is only possible to calculate soil physical properties in core samples at a microscale level if (i) volume elements are composed of only two phases, and (ii) soil samples in 3phase composition are scanned twice, first under present moisture state and second, after a complete drying or saturating to a 2-phase composition (Hainsworth and Aylmore, 1983 and 1986; Heijs et al., 1995 and 1996; Chen et al., 1996; Grose et al., 1996). The last possibility mentioned assumes that variations in water content do not cause soil structural changes, an occurrence which is never anticipated for any soil containing clay minerals. These disadvantages can be avoided by using dual en-

H. Rogasik, O. Wendroth, and M. Joschko, Center for Agricultural Landscape and Land Use Research (ZALF), Eberswalder Str. 84, D-15374 Muencheberg, Germany; J.W. Crawford, I.M. Young, and K. Ritz, Scottish Crop Research Institute, Unit of Integrative Bioscience, Invergowrie, Dundee, Scotland DD2 5DA. Received 10 March 1997. *Corresponding author (hrogasik@zalf.de).

Published in Soil Sci. Soc. Am. J. 63:741-751 (1999). ergy-level scanning, which is characterized by scanning with two different energy levels simultaneously. Important results from dual energy-level scanning with $x$-rays and $\gamma$-rays were presented by Phogat et al. (1991) and DiCarlo et al. (1997). We apply dual energy x-ray CT using a commercial scanner (i) to determine the variations of water content, dry bulk density, and phase composition at the microscale and (ii) to measure their spatial distribution in naturally structured soils. These measurements for the characterization of soil structure should enhance our knowledge regarding the impact of soil structure on water and gas transport processes.

\section{THEORY}

\section{Soil Phases, the Linear Attenuation Coefficient, and Hounsfield Unit}

The three phases of soil (solid, water, and air) contribute specifically to the attenuation of x-rays depending on their volumetric fractions. A linear relationship exists between the linear attenuation coefficient, $\mu_{\text {soil }}$, as measured for defined parts of the soil in its 3-phase composition (Hainsworth and Aylmore, 1983 and 1986; Anderson and Gantzer, 1989; Phogat et al., 1991):

$\mu_{\text {soil }}(x, y, z)=\mathrm{SV}(x, y, z) \mu_{\text {matrix }}+\mathrm{WV}(x, y, z) \mu_{\text {water }}$

where $\mu_{\text {soil }}(x, y, z)$ is the linear $\mathrm{x}$-ray attenuation coefficient $\left(\mathrm{cm}^{-1}\right)$ of a particular soil volume element as a function of its spatial coordinates $x, y$, and $z ; \mathrm{SV}(x, y, z)$ is the relative solid volume $\left(\mathrm{cm}^{3} \mathrm{~cm}^{-3}\right) ; \mathrm{WV}(x, y, z)$ is the volumetric water content $\left(\mathrm{cm}^{3} \mathrm{~cm}^{-3}\right) ; \mu_{\text {matrix }}$ is the linear $\mathrm{x}$-ray attenuation coefficient of soil matrix $\left(\mathrm{cm}^{-1}\right)$; and $\mu_{\text {water }}$ is the linear $\mathrm{x}$-ray attenuation coefficient of water $\left(\mathrm{cm}^{-1}\right)$. Converting the linear attenuation coefficient $\mu$ into Hounsfield units according to

$$
\operatorname{HU}(x, y, z)=\left[\left(\mu_{\text {soil }}(x, y, z)-\mu_{\text {water }}\right) / \mu_{\text {water }}\right] 1000
$$

has the advantage that Hounsfield units of the water phase $\left(\mathrm{HU}_{\text {water }}\right)$ and air phase $\left(\mathrm{HU}_{\text {air }}\right)$ are known and defined. Therefore, it is only necessary to calculate the matrix phase $\left(\mathrm{HU}_{\text {matrix }}\right)$, which reflects the influence of the solid component on the x-ray attenuation. Derived from Eq. [1] and [2], the following relationships between Hounsfield units and phase composition for soil volume elements can be applied for 3-phase composition:

$\mathrm{HU}(x, y, z)=\mathrm{SV}(x, y, z) \mathrm{HU}_{\text {matrix }}-1000 \mathrm{AV}(x, y, z)$

and for 2-phase composition:

$$
\begin{aligned}
(\text { solid/water }) \mathrm{HU}(x, y, z) & =\mathrm{SV}(x, y, z) \mathrm{HU}_{\text {matrix }} \\
(\text { solid/air })(\mathrm{HU}(x, y, z) & = \\
\mathrm{SV}(x, y, z) & \left(\mathrm{HU}_{\text {matrix }}+1000\right)-1000 \\
(\text { water/air })(\mathrm{HU}(x, y, z) & =\mathrm{AV}(x, y, z) \mathrm{HU}_{\text {air }}
\end{aligned}
$$

Abbreviations: CAT, computer assisted tomography; CT, computed tomography; DH, degree of heterogeneity; HU, Hounsfield unit; WMSD, weighted mean standard deviation. 
Table 1. Soil properties of the $\mathrm{Ck}_{1}$ and $\mathrm{Ck}_{2}$ horizons investigated.

\begin{tabular}{|c|c|c|c|c|c|c|c|c|c|c|c|c|}
\hline \multirow[b]{2}{*}{$\begin{array}{l}\text { Hori- } \\
\text { zon }\end{array}$} & \multirow[b]{2}{*}{$\begin{array}{c}\text { Sampling } \\
\text { depth }\end{array}$} & \multicolumn{3}{|c|}{ Particle-size distribution } & \multirow[b]{2}{*}{$\begin{array}{l}\text { Textural } \\
\text { class }\end{array}$} & \multirow[b]{2}{*}{$\begin{array}{c}\text { Water } \\
\text { content }\end{array}$} & \multirow[b]{2}{*}{$\begin{array}{c}\mathrm{C} \\
\text { total }\end{array}$} & \multirow[b]{2}{*}{$\begin{array}{c}\text { Organic } \\
\text { matter }\end{array}$} & \multirow[b]{2}{*}{$\begin{array}{c}\text { Particle } \\
\text { density }\end{array}$} & \multirow[b]{2}{*}{$\begin{array}{c}\text { Dry bulk } \\
\text { density }\end{array}$} & & \\
\hline & & $\begin{array}{c}\text { Sand } \\
>63 \mu \mathrm{m}\end{array}$ & $\begin{array}{c}\text { Silt } \\
2-63 \mu \mathrm{m}\end{array}$ & $\begin{array}{l}\text { Clay } \\
<\mathbf{2} \boldsymbol{\mu m}\end{array}$ & & & & & & & \multicolumn{2}{|c|}{$\mathbf{H U}_{\text {matrix }}$} \\
\hline & $\mathbf{c m}$ & & $\%$ & & USDA-NRCS & $\mathrm{g} \mathrm{g}^{-1}$ & - & $\%$ & $-\mathbf{g}$ & $\mathbf{n}^{-3}$ & $120 \mathrm{kV}$ & $80 \mathrm{kV}$ \\
\hline $\mathbf{C k}_{1}$ & $75-85$ & 3.3 & 82.5 & 14.2 & silt loam & 0.152 & 2.10 & 0.06 & 2.65 & 1.412 & 2300 & 2840 \\
\hline $\mathbf{C k}_{2}$ & $150-160$ & 3.1 & 80.7 & 16.2 & silt loam & 0.223 & 1.67 & $\mathbf{0 . 1 0}$ & 2.65 & 1.380 & 2290 & 2830 \\
\hline
\end{tabular}

For a 1-phase system,

$$
\text { solid: } \mathrm{HU}(x, y, z)=\mathrm{HU}_{\text {matrix }}=2000 \ldots .2600
$$

(at $120 \mathrm{kV}$ energy level, depending on textural grain size distribution and soil organic matter content)

$$
\begin{aligned}
\text { water: } & \mathrm{HU}(x, y, z)=\mathrm{HU}_{\text {water }}=0 \\
\text { air: } & \mathrm{HU}(x, y, z)=\mathrm{HU}_{\text {air }}=-1000
\end{aligned}
$$

where $\mathrm{HU}_{\text {air }}, \mathrm{HU}_{\text {water }}$, and $\mathrm{HU}_{\text {matrix }}$ denote Hounsfield units of air, water, and matrix, respectively, and $\operatorname{AV}(x, y, z)$ denotes the relative air volume $\left(\mathrm{cm}^{3} \mathrm{~cm}^{-3}\right)$ of a particular soil volume element.

\section{Hounsfield Unit and Dry Bulk Density}

Because the value of the Hounsfield unit characterizes the wet bulk density of a soil volume element, the soil water content must be known in order to estimate the dry bulk density, $\rho_{\mathrm{b}}$. From Eq. [3], the dry bulk density for a 3-phase system is

$$
\rho_{\mathrm{b}}=\rho_{\mathrm{s}}(\mathrm{HU}+1000 \mathrm{AV}) / \mathrm{HU}_{\text {matrix }}
$$

or

$$
\begin{aligned}
\rho_{\mathrm{b}}= & \rho_{\mathrm{s}} \rho_{\mathrm{w}}(\mathrm{HU}+1000) /\left[\rho_{\mathrm{w}}\left(\mathrm{HU}_{\text {matrix }}+1000\right)\right. \\
& \left.+1000 w \rho_{\mathrm{s}}\right]
\end{aligned}
$$

For a 2-phase system,

(solid, water) $\rho_{\mathrm{b}}=\rho_{\mathrm{s}} \mathrm{HU} / \mathrm{HU}_{\text {matrix }}$

(solid, air) $\rho_{\mathrm{b}}=\rho_{\mathrm{s}}(\mathrm{HU}+1000) /\left(\mathrm{HU}_{\text {matrix }}+1000\right)$

where $\rho_{\mathrm{s}}$ is the particle density $\left(\mathrm{g} \mathrm{cm}^{-3}\right), \rho_{\mathrm{w}}$ the density of water $\left(\mathrm{g} \mathrm{cm}^{-3}\right)$, and $w$ the gravimetric water content $\left(\mathrm{g} \mathrm{g}^{-1}\right)$. Linear relationships exist between the parameters $\mu$ or $\mathrm{HU}$ and the volume fraction of water $\mathrm{WV}, \rho_{\mathrm{b}}$, or $\mathrm{SV}$ of soil volume elements with coefficients of determination $r^{2}$ close to unity (Petrovic et al., 1982; Crestana et al., 1986; Anderson and

\begin{tabular}{|c|c|c|c|c|}
\hline \multirow{2}{*}{$\begin{array}{l}\text { Voxel size } \\
\text { Edge length }\end{array}$} & \multicolumn{2}{|c|}{ Number } & \multicolumn{2}{|c|}{ Parameter } \\
\hline & Voxel/cube & Pixel/voxel & Measured & Calculated \\
\hline \multicolumn{5}{|l|}{$\mathbf{m m}$} \\
\hline $0.25 \times 0.25 \times 1$ & 2352000 & $\mathbf{1}$ & HU & - \\
\hline $0.5 \times 0.5 \times 1$ & 588000 & 4 & - & HU, SD \\
\hline $1 \times 1 \times 1$ & 147000 & 16 & - & HU, SD \\
\hline $2 \times 2 \times 2$ & 18375 & 128 & - & HU, SD \\
\hline $5 \times 5 \times 5$ & 1176 & 2000 & - & HU, SD \\
\hline $10 \times 10 \times 10$ & 147 & 16000 & - & HU, SD \\
\hline $70 \times 70 \times 30$ & 1 & 2352000 & - & HU, SD \\
\hline
\end{tabular}
Gantzer, 1987; Anderson et al., 1988; Phogat and Aylmore, 1989; Tollner and Verma, 1989; Vaz et al., 1989; Cruvinel et al., 1990; Hopmans et al., 1992).

Table 2. Voxel sizes related to the reference cube of $70 \times 70 \times$ $30 \mathrm{~mm}$.

\section{Comparison of Hounsfield Unit Values Measured for the Two Different Energy Levels}

The attenuation of $80 \mathrm{kV}$ x-rays is greater than that of $120 \mathrm{kV}$ x-rays. Because the HU values of air and water are independent of energy level scanning (Wegener, 1992), the difference in attenuation depends on the volumetric fraction of the solid matrix. In the case of a 2-phase system consisting of water and air, the difference between the attenuation of 80 and $120 \mathrm{kV} \mathrm{x}$-rays is minimal and equal to zero. The maximum possible difference between measured HU values at 80 and $120 \mathrm{kV}$ corresponds to the difference between $\mathrm{HU}_{\text {matrix }}(80$ $\mathrm{kV})$ and $\mathrm{HU}_{\text {matrix }}(120 \mathrm{kV})$.

\section{Calculation of Phase Composition of Volume Elements within a Soil Core}

By scanning soil cores at two different energy levels, the phase composition of each volume element can be calculated by solving two equations with two unknown variables.
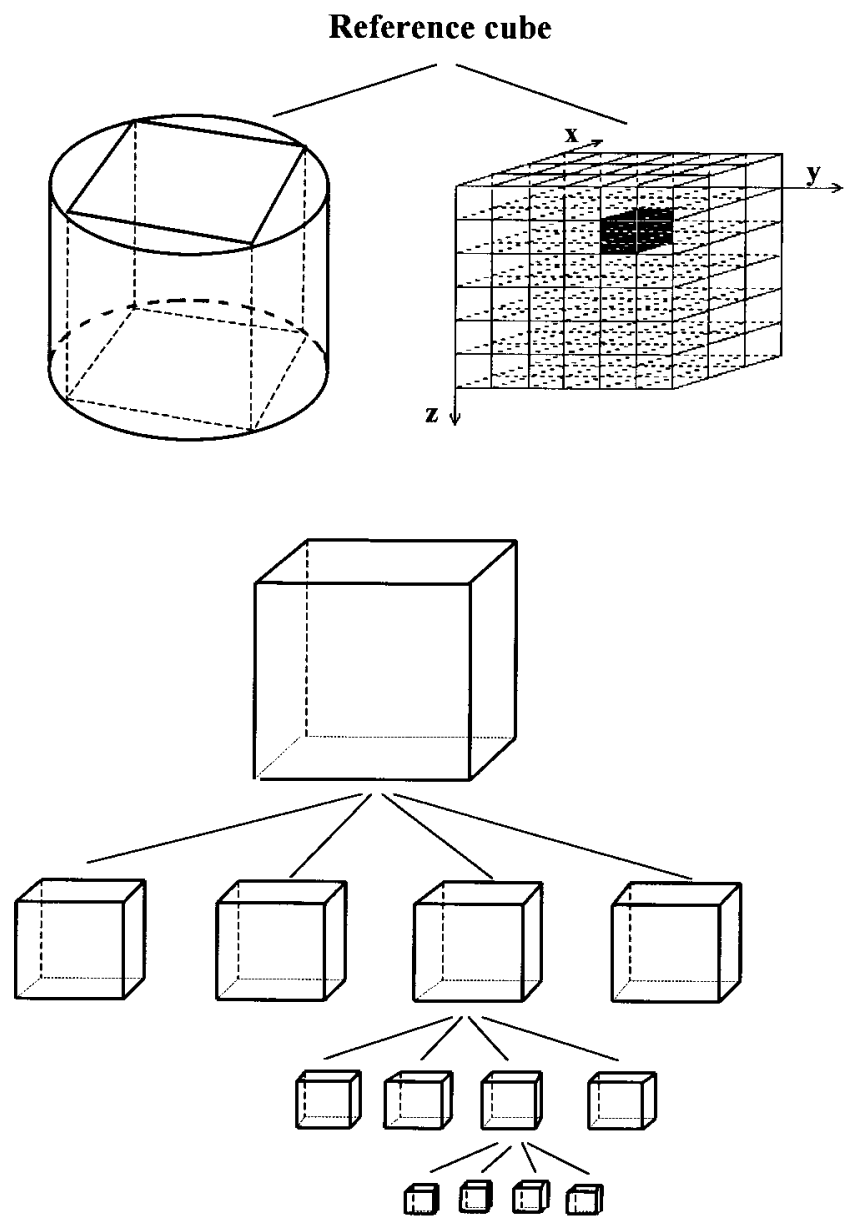

Fig. 1. The scheme of dividing the reference cube into voxels of different sizes. 
For a 3-phase system, Eq. [3] may be written as

$$
\begin{aligned}
& \mathrm{HU}_{1}=\mathrm{SVH} \mathrm{HU}_{\text {matrix1 }}-1000 \mathrm{AV} \\
& \mathrm{HU}_{2}=\mathrm{SV} \mathrm{HU} \mathrm{H}_{\text {matrix } 2}-1000 \mathrm{AV}
\end{aligned}
$$

where subscripts 1 and 2 refer to the high and low energy radiation levels, respectively. Variables $\mathrm{HU}_{1}$ and $\mathrm{HU}_{2}$ are each measured directly. Variables $\mathrm{HU}_{\text {matrix } 1}$ and $\mathrm{HU}_{\text {matrix } 2}$ are estimated from calibration measurements on standard soil cores using Eq. [3], [4], or [5]. The unknown variables SV and AV, solved from Eq. [11a] and [12a], can be written

$$
\begin{aligned}
\mathrm{SV}= & \left(\mathrm{HU}_{2}-\mathrm{HU}_{1}\right) /\left(\mathrm{HU}_{\text {matrix2 }}-\mathrm{HU}_{\text {matrix1 }}\right) \\
\mathrm{AV}= & \left(\mathrm{HU}_{2} \mathrm{HU}_{\text {matrix1 }}-\mathrm{HU}_{1} \mathrm{HU}_{\text {matrix } 2}\right) / \\
& 1000\left(\mathrm{HU}_{\text {matrix } 2}-\mathrm{HU}_{\text {matrix1 }}\right)
\end{aligned}
$$
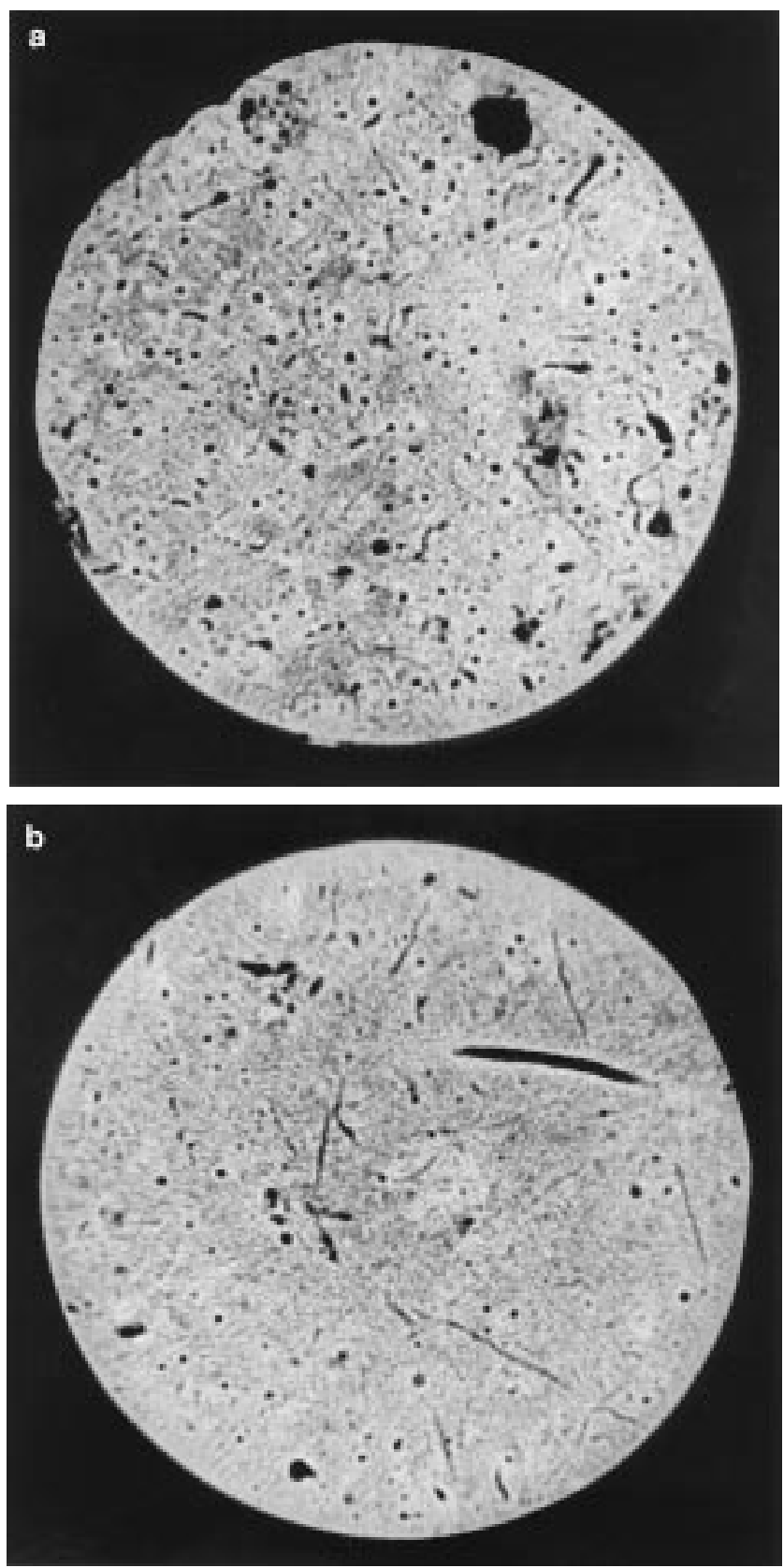

Fig. 2. Representative $\mathrm{x}$-ray images from the core of (a) $\mathbf{C k}_{1}$ horizon and (b) $\mathrm{Ck}_{2}$ horizon.
The parameters $\mathrm{WV}, \rho_{\mathrm{b}}$, and $w$ are calculated from

$$
\begin{aligned}
\mathrm{WV} & =1-(\mathrm{SV}+\mathrm{AV}) \\
\rho_{\mathrm{b}} & =\rho_{\mathrm{s}} \mathrm{SV} \\
w & =\mathrm{WV} \rho_{\mathrm{w}} / \rho_{\mathrm{b}}
\end{aligned}
$$

\section{MATERIALS AND METHODS}

\section{Soils}

Undisturbed soil core samples were taken from a Chernozem (FAO classification) or Mollisol/Boroll (Soil Survey Staff, 1975) from two similar, coherent subsoil Ck horizons. Both height and inside diameter of the cylindric cores were 100 $\mathrm{mm}$. Soil properties measured for each horizon are shown in Table 1. Comparing the samples of the two horizons, those taken from the shallower depth of 75 to $85 \mathrm{~cm}\left(\mathrm{Ck}_{1}\right)$ were characterized by a greater dry bulk density and a smaller water content during CT scanning than those the deeper depth of 150 to $160 \mathrm{~cm}\left(\mathrm{Ck}_{2}\right)$

\section{Scanning System}

The investigation was carried out with a Siemens Somatom Plus-CT scanner (Siemens, Erlangen, Germany) at energy levels of $80 \mathrm{kV}(190 \mathrm{~mA}, 760 \mathrm{mAs})$ and $120 \mathrm{kV}(85 \mathrm{~mA}, 340$ $\mathrm{mAs}$ ). The scan time was $2 \times 2 \mathrm{~s}$ (multiscan technique). The reconstruction matrix consisted of 512 by 512 pixels. The scanner is constructed of a continuously rotating fan beam-measuring system, a source of $\mathrm{x}$-ray rigid-coupled with detectors, a spot size for the fan beam of $1.3 \times 1.2 \mathrm{~mm}$ or $0.8 \times 0.9 \mathrm{~mm}$, a detector consisting of 768 multi-use chambers, and a scanning system based on 1536 measuring channels.

\section{Methods}

The soil samples were scanned horizontally at both the 80and $120-\mathrm{kV}$ energy levels before shifting the core vertically at a 1-mm distance to perform the next scan. This procedure precluded registration problems that occur when a core is scanned completely at one energy level, and then repositioned for scanning at the next energy level. The pixel size is $0.25 \times$ $0.25 \mathrm{~mm}$. It was calculated as the inner diameter of the core divided by the number of pixels of the reconstruction matrix, obtained under the chosen zoom factor of 4.0.

For morphological investigations, based on different voxel

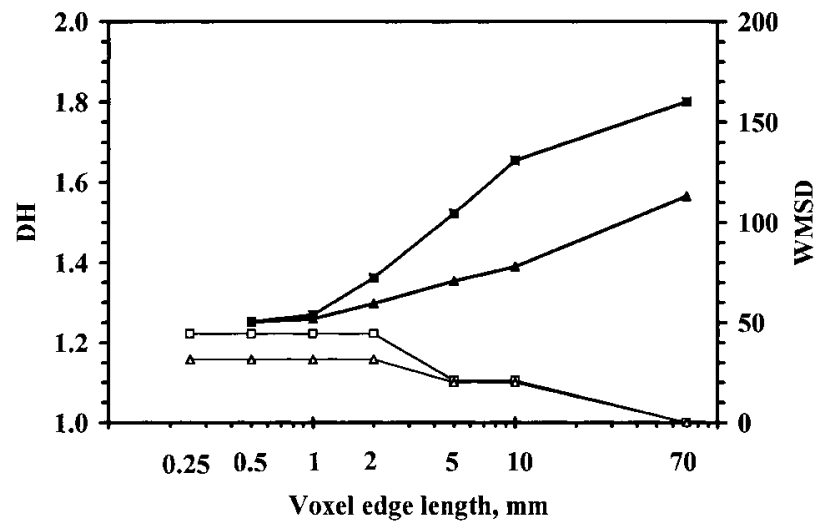

$\rightarrow$ Ck1, DH $\rightarrow-$ Ck2, DH $\rightarrow$ Ck1, WMSD $\rightarrow$ Ck2, WMSD

Fig. 3. Internal (WMSD) and external (DH) heterogeneity vs. voxel size: a comparison between the soil samples from the $\mathrm{Ck}_{1}$ and $\mathrm{Ck}_{2}$ horizons. 
Ck1 horizon, $x=30$

Voxel edge length: $1 \mathrm{~mm}$
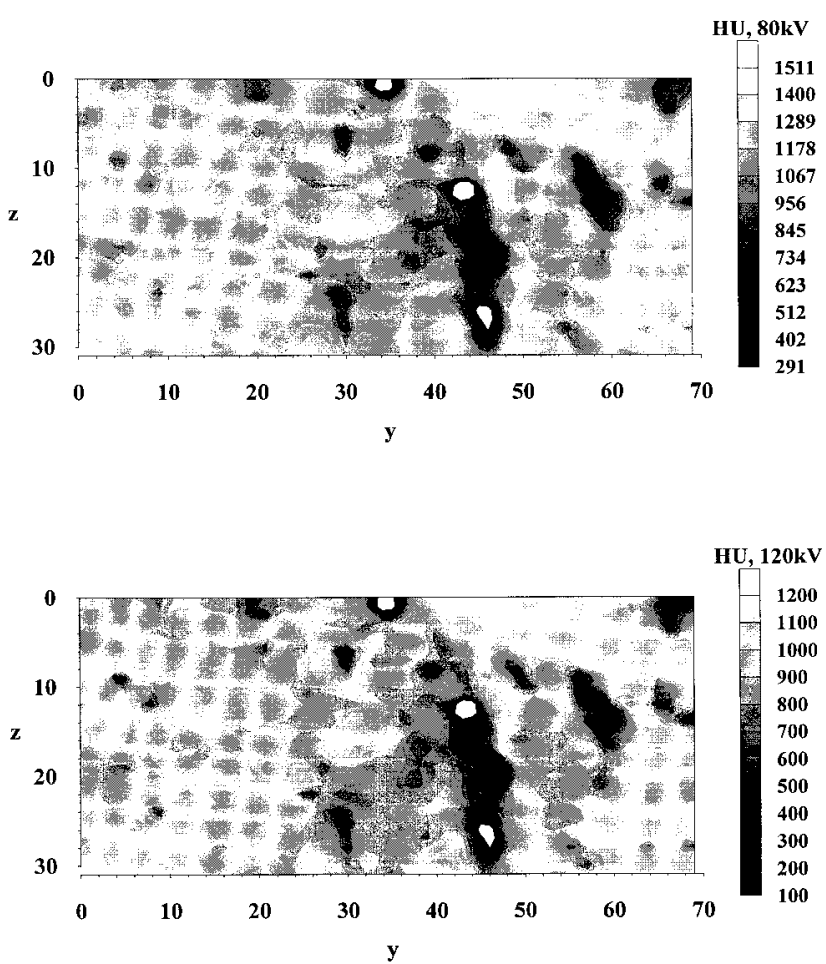

Fig. 4. Spatial distribution of Hounsfield units within a selected vertical slice of a $\mathrm{Ck}_{1}$ soil core sample compared for 80 and $120 \mathrm{kV}$ energy level at 1-mm voxel edge length.

sizes, which require a unique volume of the reference object, we computationally inscribed within the soil cylinder the largest possible parallelepiped (the so-called reference cube) with an edge length of $70 \times 70 \times 90 \mathrm{~mm}$. The pixels located inside this reference cube were computationally aggregated stepwise to voxels of increasing size, which as a whole built the reference cube again (Table 2). Based on Hounsfield units of pixels, average HU values and standard deviations for each voxel size were calculated. Then using a downscaling procedure, the reference cube was divided into the same considered smaller cubic volume elements with edge lengths of $10,5,2$, $1,0.5$, and $0.25 \mathrm{~mm}$, respectively (Fig. 1). Thus, we were able to investigate in which manner and to what extent the stepwise dividing of reference cube into smaller volume elements up to pixel size actually increased the number of covered HUclasses and decreased the internal heterogeneity (SD) of voxels. The soil structural heterogeneity was quantified via fre-

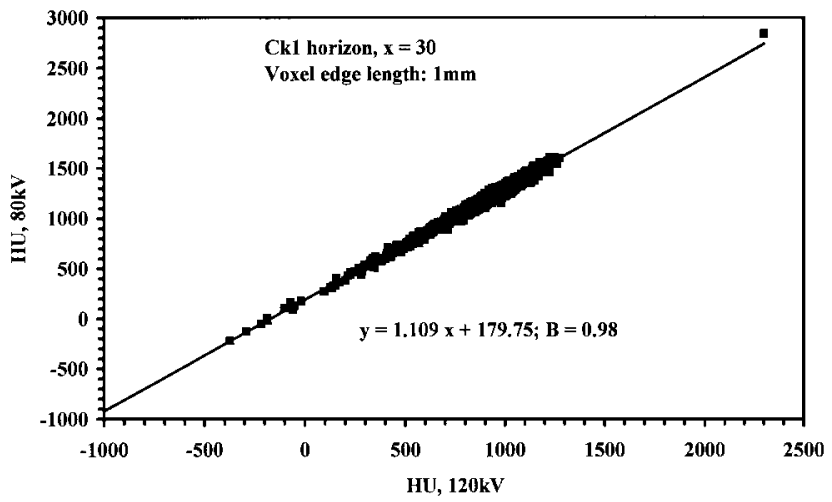

Fig. 5. Relationship between Hounsfield units at $80 \mathrm{kV}$ and $120 \mathrm{kV}$ from the selected vertical slice of a $\mathrm{Ck}_{1}$ soil core sample at $1-\mathrm{mm}$ voxel edge length.
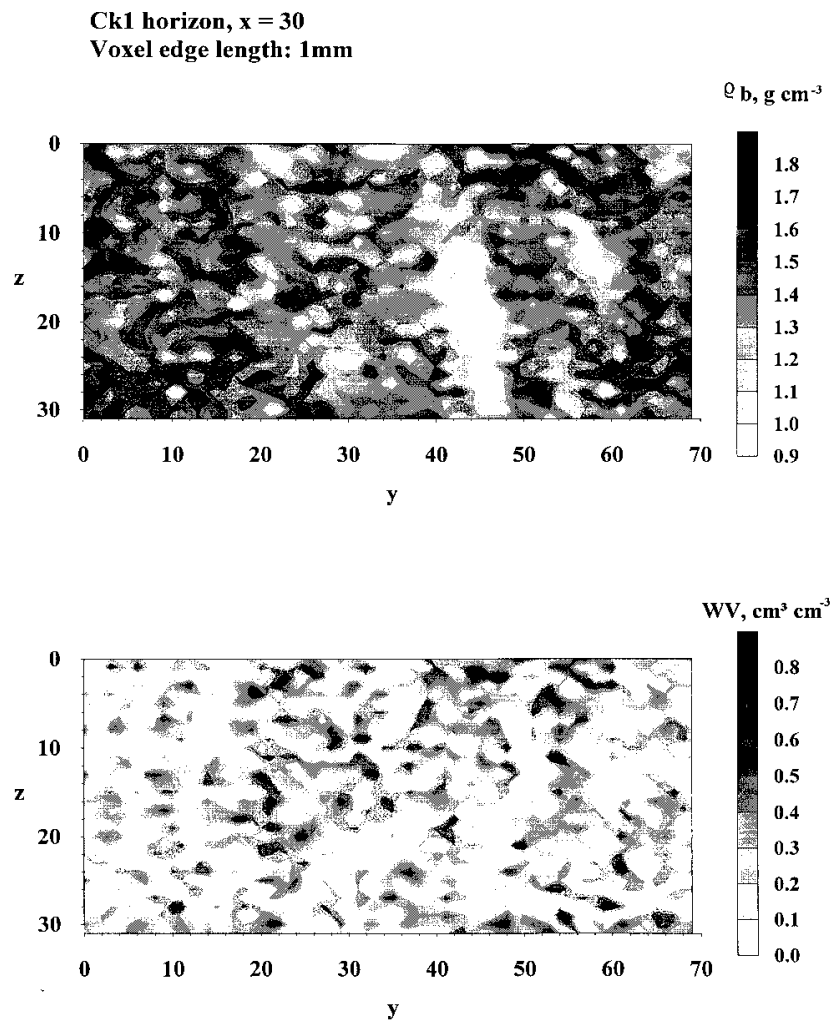

Fig. 6. Spatial distribution of soil bulk density and relative water volume within a selected vertical slice of a $\mathbf{C k}_{1}$ soil core sample at 1-mm voxel edge length.

quency distributions of classified HU and SD values for every discretization stage; e.g., voxel size (Rogasik et al., 1994).

For calculation of degree of heterogeneity (DH), as a measure for external heterogeneity, the histograms of covered $\mathrm{HU}$-classes for all voxel sizes were converted into cumulative curves of covered HU-classes. DH was estimated as follows:

$$
\mathrm{DH}=\frac{\begin{array}{c}
\text { covered HU-class at } 95 \% \\
\text { of cumulative frequency }
\end{array}}{\text { covered HU-class at } 95 \%}
$$

Hence, the quotient DH is a measure of the narrow-spaced structural composition of the undisturbed soil samples. The more heterogeneous a soil or medium is, the greater is the $\mathrm{DH}$. The curve shape of DH vs. voxel size provides additional information. A marked increase in the DH curve is evidence for an incipient identification of soil structural elements.

Based on histograms of covered SD-classes and dependent upon the edge length of the voxels, the HU weighted mean standard deviation (WMSD) as a measure for internal heterogeneity was calculated as follows:

$$
\mathrm{WMSD}=\sum_{i=1}^{n} \mathrm{SD} \operatorname{class}(i) \cdot f(i)
$$

where $f(i)$ denotes the relative percentage of voxels within the respective SD class.

The parameter WMSD describes the internal heterogeneity by quantifying the changes of pixel-related standard deviation of voxels, depending on their size. The stepwise division of the reference cube into smaller voxels leads to a decrease of the WMSD values, because the voxel size and the sizes of structural elements begin to correspond. In this case, the voxels consist of relatively homogeneous structural elements, such as aggregates or macropores, which are characterized by very 

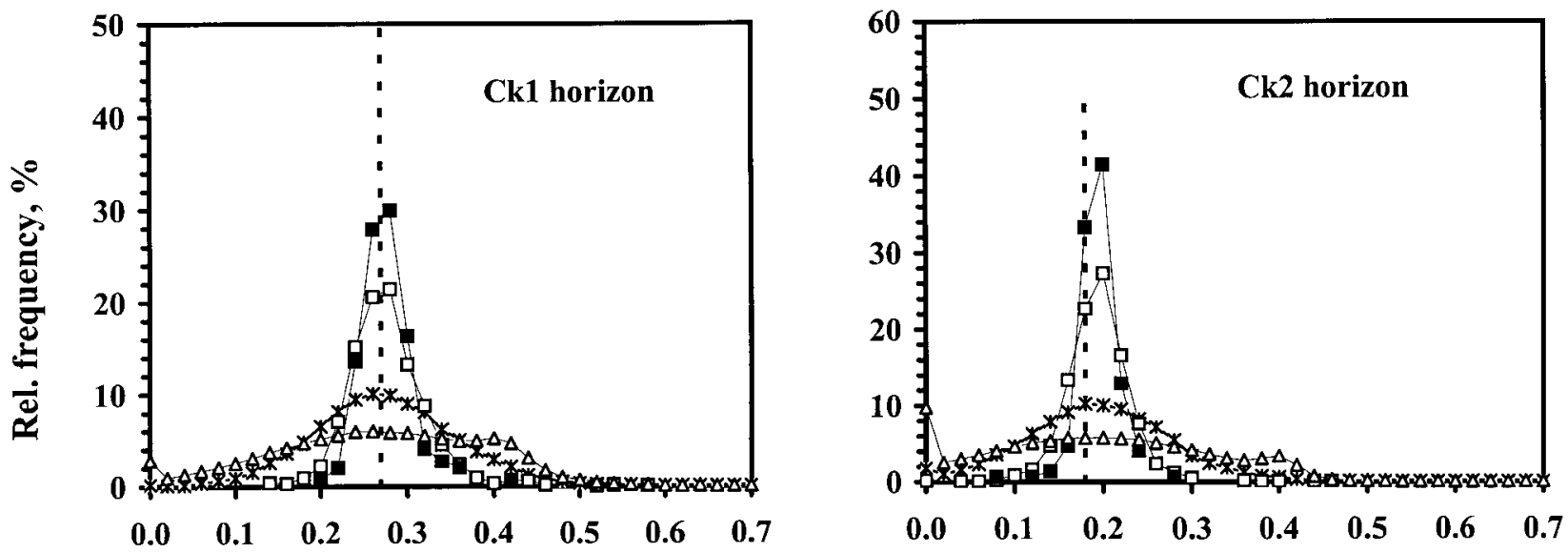

Air volume, $\mathrm{cm}^{3} \mathrm{~cm}^{-3}$

\section{Voxel edge length}

$$
-\triangle 1 \mathrm{~mm} \rightarrow-2 \mathrm{~mm} \rightarrow-0 \mathrm{~mm} \rightarrow-10 \mathrm{~mm} \cdots \text { mean }
$$

Fig. 7. Frequency of air volume classes for various voxel edge lengths in the cores of $\mathbf{C k}_{1}$ and $\mathrm{Ck}_{2}$ horizons.

little internal heterogeneity. The more heterogeneous a soil or a porous medium is, the greater the WMSD. The extent to which the division of the reference cube into smaller voxel sizes leads to a decrease of the WMSD value depends on the specific soil structure.

Both parameters DH and WMSD describe the same process from different points of view. The larger the $\mathrm{DH}$ values of pixels or the WMSD values of the reference cube, the more heterogeneous is the soil core. Hence, an absolute homogeneous medium is characterized by a $\mathrm{DH}$ value that is equal to 1 and a WMSD value equal to 0 , regardless of the voxel size.

For this study, we present an analysis of dual energy measurements conducted for only the upper $30 \mathrm{~mm}$ of soil cores. The number of data sets for every discretization stage is shown in Table 2.

\section{RESULTS AND DISCUSSION}

Representative $\mathrm{x}$-ray images from cores of $\mathrm{Ck}_{1}$ and $\mathrm{Ck}_{2}$ horizon (Fig. 2a and 2b) show a relatively coherent structure characterized by a larger pore scale resulting from earthworm activity and rooting processes. The core belonging to the $\mathrm{Ck}_{1}$ horizon is more heterogeneous than that belonging to the $\mathrm{Ck}_{2}$ horizon. The evidence is given by the calculated parameters $\mathrm{DH}$ and WMSD, which characterize the external and internal heterogeneity and show higher values for the $\mathrm{Ck}_{1}$ core in comparison to those from the $\mathrm{Ck}_{2}$ horizon (Fig. 3).

\section{Spatial Distribution of Hounsfield Units Measured for Voxels at a Selected Vertical Slice at $80 \mathrm{kV}$ and $120 \mathrm{kV}$ Energy Levels: A Comparison}

The spatial distribution of HUs within a vertical slice of a soil core sample from the $\mathrm{Ck}_{1}$ horizon, compared at the 80 and $120 \mathrm{kV}$ energy levels, shows excellent agreement in narrow-spaced differentiation at 1-mm voxel edge length resolution (Fig. 4). For a better visualization of the agreement between both energy levels, the association of gray-level classes for HUs at 80 and
$120 \mathrm{kV}$ was standardized, based on the calculated linear regression function $y(\mathrm{HU} 80 \mathrm{kV})=a \times(\mathrm{HU} 120 \mathrm{kV})+$ $b$ with a coefficient of determination of $r^{2}=0.98$ (Fig. 5). Of note in Fig. 4 is the occurrence of a large vertically oriented zone of lower HUs, which is reflected by a

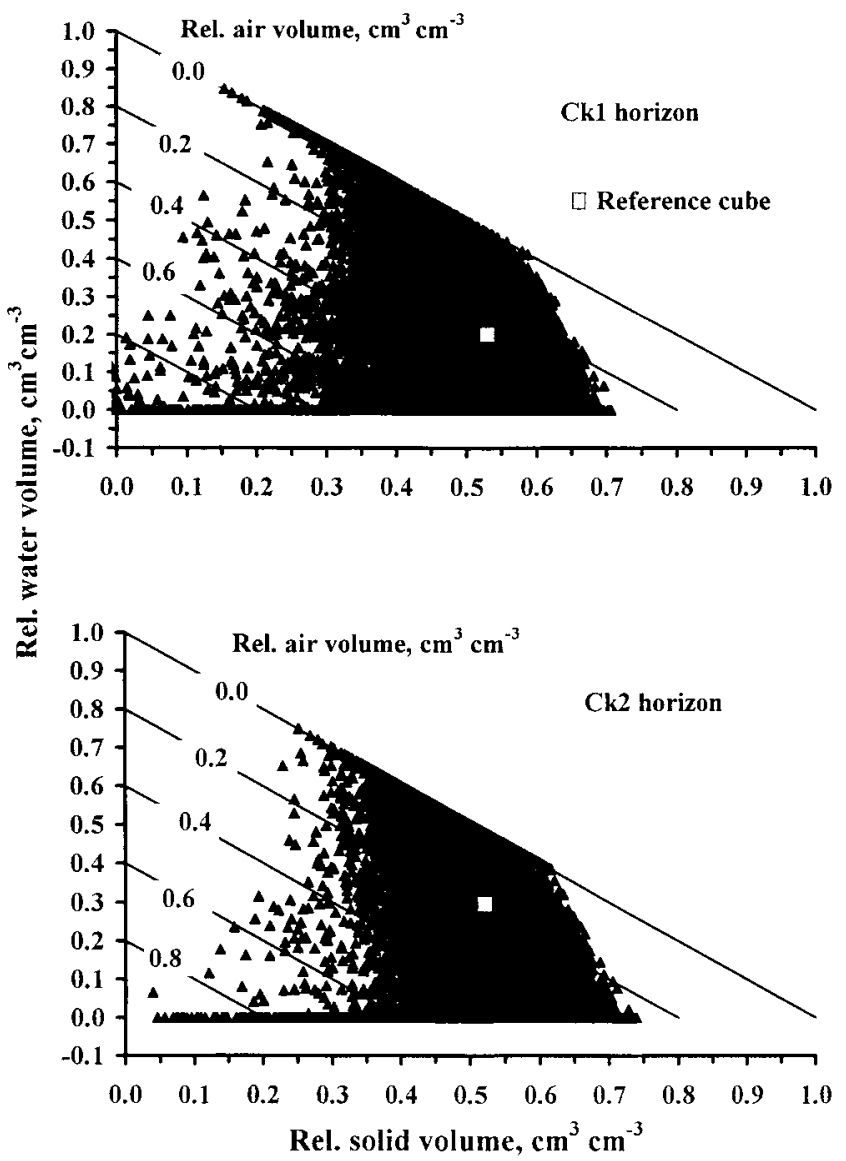

Fig. 8. Characterization of multi-phase composition for voxels with edge length of $1 \mathrm{~mm}$ from cores of $\mathrm{Ck}_{1}$ and $\mathrm{Ck}_{2}$ horizons in comparison to reference cube. 
Table 3. Mean and standard deviation of the fraction of solid (SV), water (WV), and air (AV) for the soil samples of $\mathrm{Ck}_{1}$ and $\mathrm{Ck}_{2}$ horizons and for different voxel edge lengths.

\begin{tabular}{|c|c|c|c|c|c|c|c|c|c|c|c|}
\hline \multirow[b]{3}{*}{ Horizon } & \multirow[b]{3}{*}{ Parameter } & \multirow{3}{*}{$\begin{array}{l}\text { Core } \dagger \\
\text { Mean }\end{array}$} & \multicolumn{9}{|c|}{ Edge length of voxels } \\
\hline & & & \multirow{2}{*}{$\begin{array}{c}70 \mathrm{~mm}+ \\
\text { Mean }\end{array}$} & \multicolumn{2}{|c|}{$10 \mathrm{~mm}$} & \multicolumn{2}{|c|}{$5 \mathrm{~mm}$} & \multicolumn{2}{|c|}{$2 \mathrm{~mm}$} & \multicolumn{2}{|c|}{$1 \mathrm{~mm}$} \\
\hline & & & & Mean & SD & Mean & SD & Mean & SD & Mean & SD \\
\hline & & & & & & ${ }^{3} \mathbf{c m}^{-3}$ & & & & & \\
\hline $\begin{array}{l}\mathbf{C k}_{1} \\
\mathbf{C k _ { 2 }}\end{array}$ & $\begin{array}{l}\text { SV } \\
\text { SV }\end{array}$ & $\begin{array}{l}\mathbf{0 . 5 3 3} \\
\mathbf{0 . 5 2 1}\end{array}$ & $\begin{array}{l}0.530 \\
0.520\end{array}$ & $\begin{array}{l}0.529 \\
0.521\end{array}$ & $\begin{array}{l}0.022 \\
0.017\end{array}$ & $\begin{array}{l}0.529 \\
0.521\end{array}$ & $\begin{array}{l}0.029 \\
0.022\end{array}$ & $\begin{array}{l}0.528 \\
0.521\end{array}$ & $\begin{array}{l}0.045 \\
0.039\end{array}$ & $\begin{array}{l}\mathbf{0 . 5 2 7} \\
\mathbf{0 . 5 2 2}\end{array}$ & $\begin{array}{l}0.068 \\
0.056\end{array}$ \\
\hline $\begin{array}{l}\mathbf{C} \mathbf{k}_{1} \\
\mathbf{C k _ { 2 }}\end{array}$ & $\begin{array}{l}\text { WV } \\
\text { WV }\end{array}$ & $\begin{array}{l}0.214 \\
0.308\end{array}$ & $\begin{array}{l}0.207 \\
0.298\end{array}$ & $\begin{array}{l}0.210 \\
0.295\end{array}$ & $\begin{array}{l}0.034 \\
0.024\end{array}$ & $\begin{array}{l}0.210 \\
0.294\end{array}$ & $\begin{array}{l}0.048 \\
0.041\end{array}$ & $\begin{array}{l}0.205 \\
0.294\end{array}$ & $\begin{array}{l}0.103 \\
0.108\end{array}$ & $\begin{array}{l}0.206 \\
0.291\end{array}$ & $\begin{array}{l}0.169 \\
0.166\end{array}$ \\
\hline $\begin{array}{l}\mathbf{C k}_{1} \\
\mathbf{C k}_{2}\end{array}$ & $\begin{array}{l}\text { AV } \\
\text { AV }\end{array}$ & $\begin{array}{l}0.253 \\
0.172\end{array}$ & $\begin{array}{l}0.264 \\
0.184\end{array}$ & $\begin{array}{l}0.262 \\
0.185\end{array}$ & $\begin{array}{l}0.030 \\
0.022\end{array}$ & $\begin{array}{l}0.262 \\
0.185\end{array}$ & $\begin{array}{l}0.046 \\
0.037\end{array}$ & $\begin{array}{l}0.266 \\
0.185\end{array}$ & $\begin{array}{l}0.090 \\
0.085\end{array}$ & $\begin{array}{l}0.266 \\
0.187\end{array}$ & $\begin{array}{l}0.127 \\
0.125\end{array}$ \\
\hline
\end{tabular}

$\dagger$ Measured for the bulk sample, based on weighing.

\$Reference cube.

region of lower bulk density and lower relative water volume (see Fig. 6). Zones of low relative water volume are associated with both loose and dense regions.

The good agreement in HUs at both energy levels is evidence for the quality of dual energy-level scanning. The narrow-spaced heterogeneity in HUs, as well as in derived soil physical parameters, characterizes good quality in soil phase differentiation as a result of dual energy-level scanning.

\section{Phase Composition of Volume Elements}

The calculation of phase composition of each voxel initially assumes a 3-phase composition. If we obtain a volumetric fraction of $<0$ or $>1$ for any of the three phases for a particular voxel, that voxel must comprise only two phases. The decision about whether the composition is solid and water or solid and air depends on the solution of the relevant set of simultaneous equations. If the difference between the SVs calculated from Eq. [11b] and Eq. [12b] below approaches zero, then the phases are solid and water.

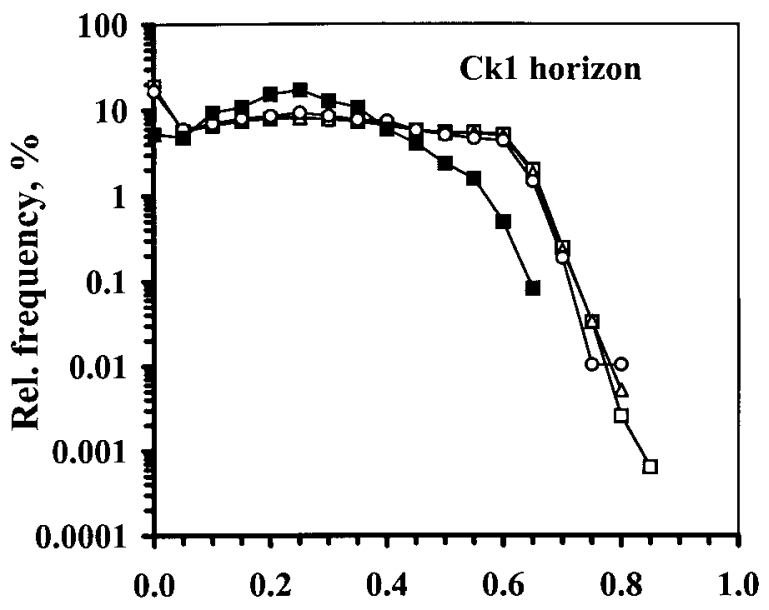

$$
\begin{aligned}
& \mathrm{SV}_{1}=\mathrm{HU}_{1} / \mathrm{HU}_{\text {matrix } 1} \\
& \mathrm{SV}_{2}=\mathrm{HU}_{2} / \mathrm{HU}_{\text {matrix } 2}
\end{aligned}
$$

Alternatively, if the difference between the SVs calculated from Eq. [11c] and Eq. [12c] below approaches zero, then the voxel comprises a composition of solid and air.

$$
\begin{array}{ll}
\mathrm{SV}_{1}=\left(\mathrm{HU}_{1}+1000\right) /\left(\mathrm{HU}_{\text {matrix } 1}+1000\right) & {[11 \mathrm{c}]} \\
\mathrm{SV}_{2}=\left(\mathrm{HU}_{2}+1000\right) /\left(\mathrm{HU}_{\text {matrix } 2}+1000\right) & {[12 \mathrm{c}]}
\end{array}
$$

With a voxel edge length decreasing to $1 \mathrm{~mm}$, the variability in the soil phases between the volume elements increases markedly (Fig. 7 and 8, Table 3). At resolutions below $1 \mathrm{~mm}$, the frequency distributions of water, air, and solid volumes are only insignificantly different (Fig. 9, 10, and 11). One explanation could be that the further increase in resolution can be carried out only in two dimensions, since the minimum slice thickness of scanned objects is fixed by the scanning system at $1 \mathrm{~mm}$. Another explanation for the insignificant changes in frequency distributions of soil phases below 1-mm reso-

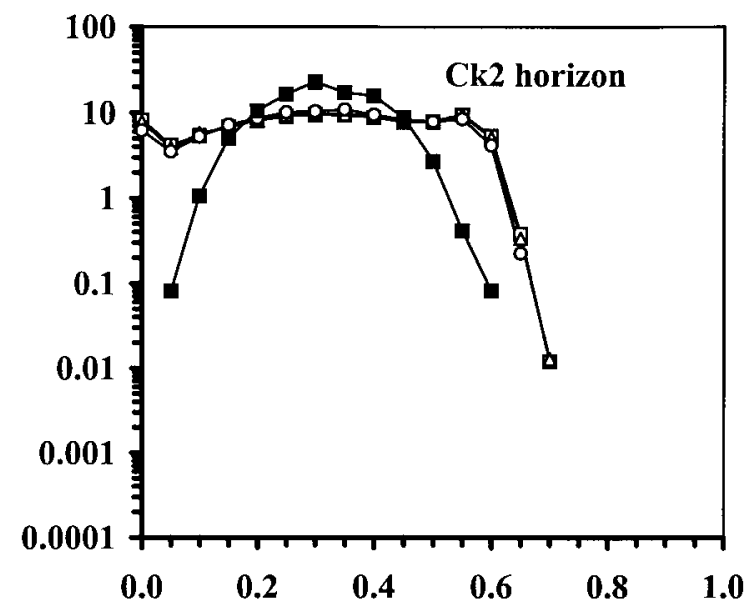

Water volume, $\mathrm{cm}^{3} \mathrm{~cm}^{-3}$

\section{Voxel edge length}

$\rightarrow-2 \mathrm{~mm} \rightarrow-1 \mathrm{~mm} \rightarrow-0.5 \mathrm{~mm} \rightarrow-0.25 \mathrm{~mm}$

Fig. 9. Frequency of water volume classes for the smallest voxels and pixels from selected horizontal slices in the cores of $\mathrm{Ck}_{1}$ and $\mathrm{Ck}_{2}$ horizons. 

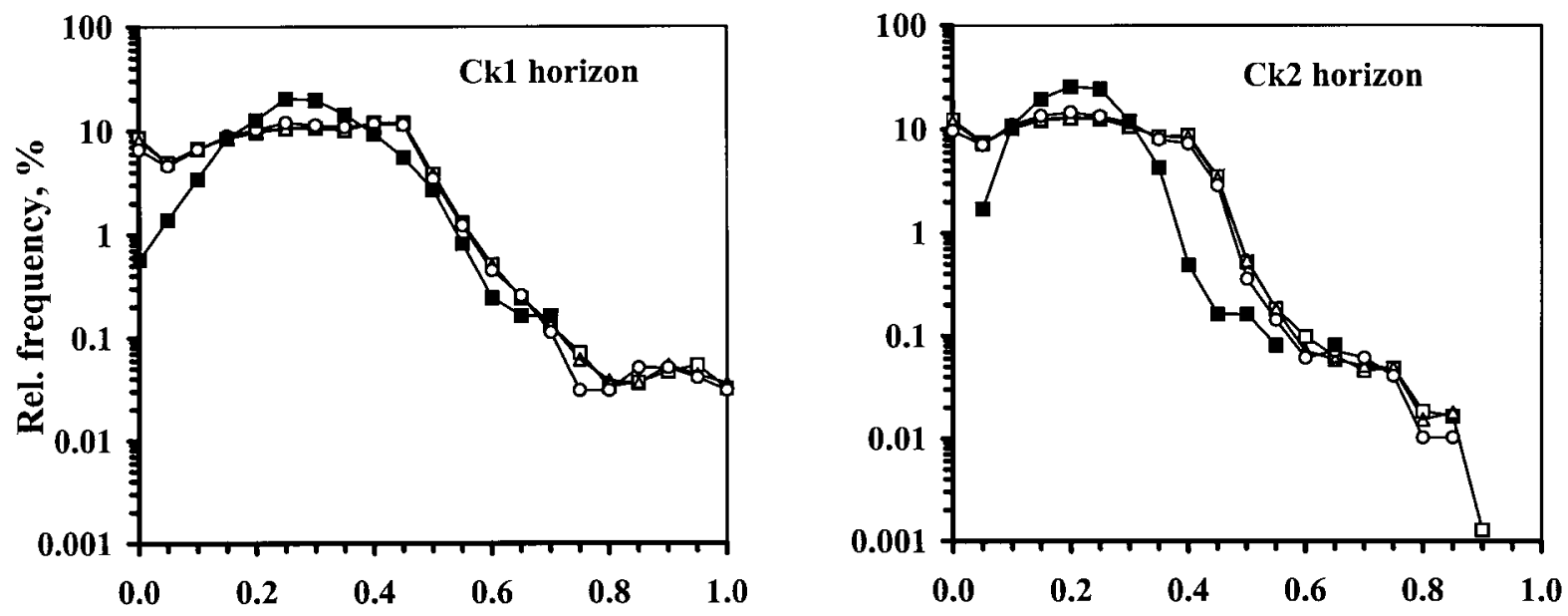

Air volume, $\mathrm{cm}^{3} \mathrm{~cm}^{-3}$

Voxel edge length

$\rightarrow-2 \mathrm{~mm} \multimap-1 \mathrm{~mm} \rightarrow 0.5 \mathrm{~mm} \rightarrow-0.25 \mathrm{~mm}$

Fig. 10. Frequency of air volume classes for the smallest voxels and pixels from selected horizontal slices in the cores of $\mathrm{Ck}_{1}$ and $\mathrm{Ck}_{2} \mathrm{horizons}$

lution is the coherent structure of these silt loams. At the maximum resolution the majority of the larger scale pores is identified predominantly as a 2-phase composition of solid and air. Results from selected horizontal slices show that at a 1-mm voxel edge length resolution, the histograms for relative water and air volumes are characterized by a marked plateau (Fig. 9 and 10), unlike the Gaussian bell-shaped curve observed for resolutions $>2 \mathrm{~mm}$. The relatively heterogeneous voxels from the former dominantly covered-parameter class at 2-mm resolution have been divided into a broader spectrum of more homogeneous subunits. As a result, not only

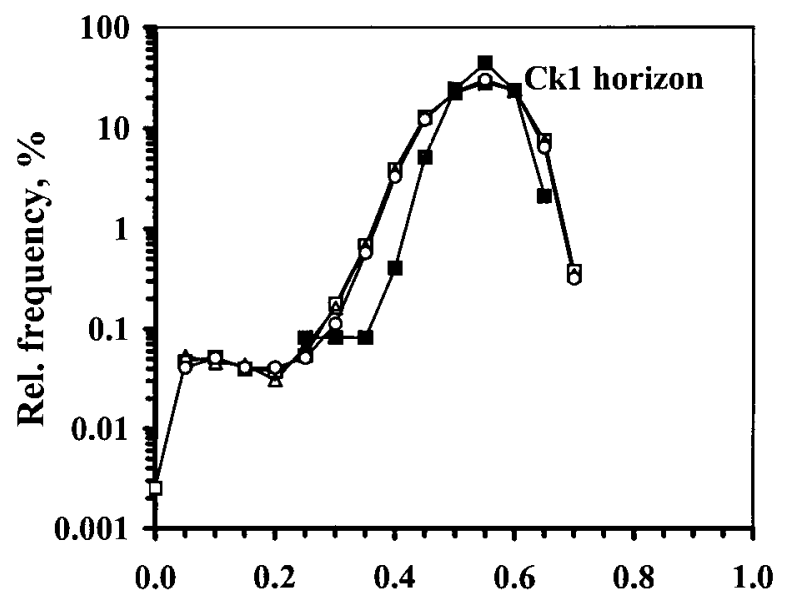

the zero class of both parameters, which includes the fraction of voxels or pixels in corresponding 2-phase composition, but many neighbored-parameter classes increased markedly as well. The results show that for the case of the coherent silt loam soil, the $1-\mathrm{mm}$ voxel edge length resolution is small enough to characterize the phase composition, as well as to detect zones of weakness or macropores that are responsible for preferential flow phenomena.

Regardless of the resolution, the variability in soil phase composition of the $\mathrm{Ck}_{1}$ horizon is greater than that of the $\mathrm{Ck}_{2}$ horizon (Fig. 8). For the investigated

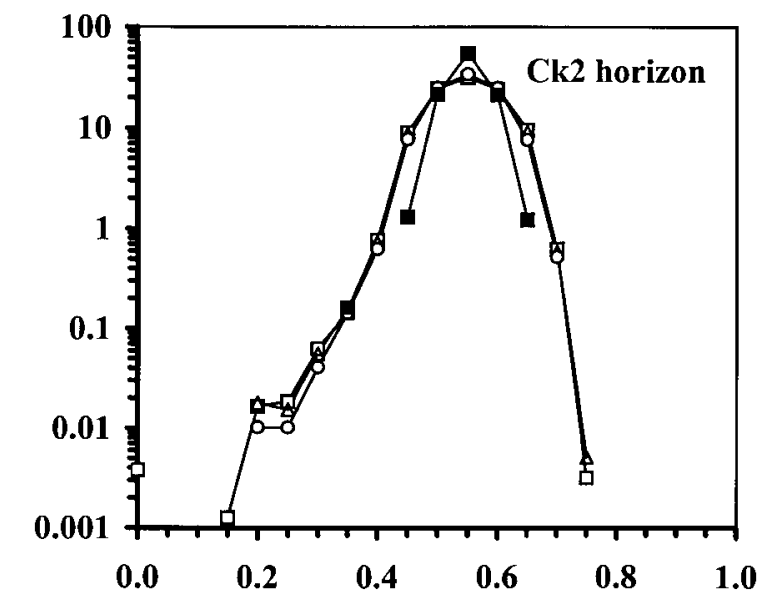

Solid volume, $\mathrm{cm}^{3} \mathrm{~cm}^{-3}$

Voxel edge length

$\rightarrow 2 \mathrm{~mm} \multimap-1 \mathrm{~mm} \rightarrow-0.5 \mathrm{~mm} \rightarrow-0.25 \mathrm{~mm}$

Fig. 11. Frequency of solid volume classes for the smallest voxels and pixels from selected horizontal slices in the cores of $\mathrm{Ck}_{1}$ and $\mathrm{Ck}_{2}$ horizons. 

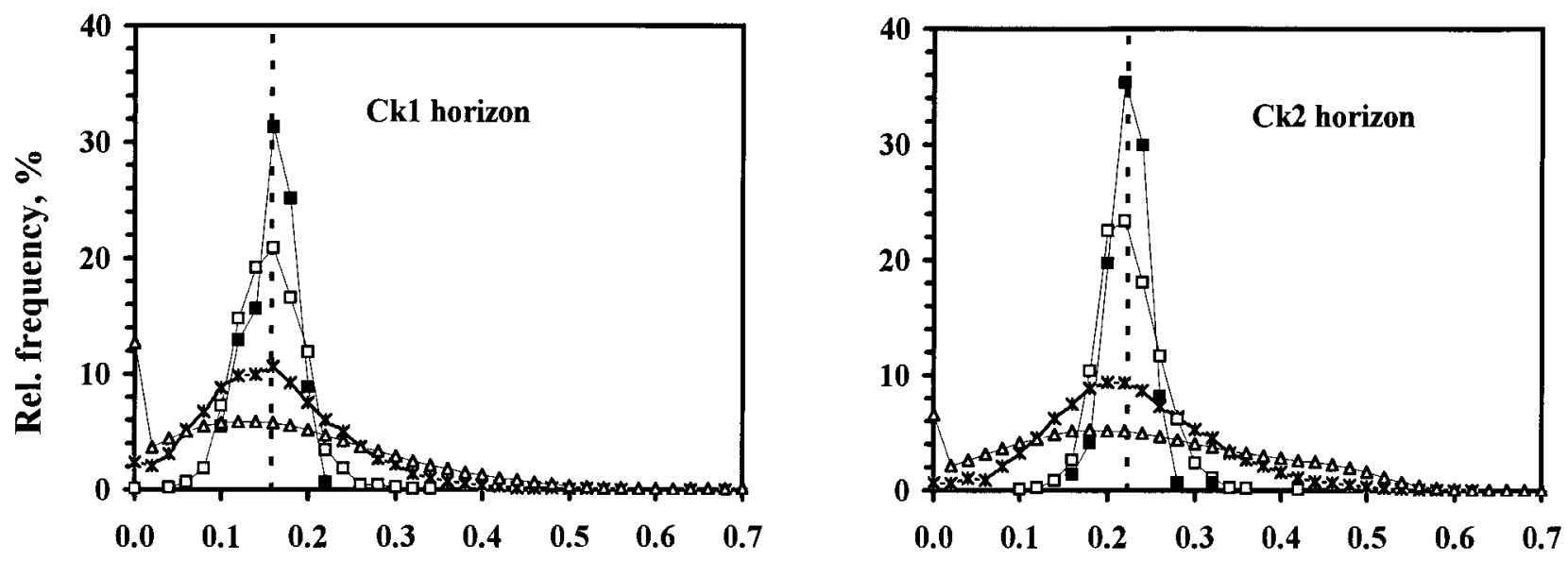

Gravimetric water content, $\mathrm{g} \mathrm{g}^{-1}$

\section{Voxel edge length \\ $\triangle 1 \mathrm{~mm} \rightarrow-2 \mathrm{~mm} \rightarrow-\mathrm{mm} \rightarrow 10 \mathrm{~mm}-\cdots$ mean}

Fig. 12. Frequency of gravimetric water content classes for various voxel edge lengths in the cores of $\mathrm{Ck}_{1}$ and $\mathrm{Ck}_{2}$ horizons.

voxel sizes, the weighted mean of the derived volumetric water, air, and solid contents agrees with the sample's phase composition (Table 3). That can be considered as a measure of plausibility and evidence for the accuracy of scanning (Phogat et al., 1991).

\section{Heterogeneity of Water Content at the Microscale Level}

The soil cores are characterized by average gravimetric water contents of $0.152 \mathrm{~g} \mathrm{~g}^{-1}$ for the $\mathrm{Ck}_{1}$ horizon and $0.223 \mathrm{~g} \mathrm{~g}^{-1}$ for the $\mathrm{Ck}_{2}$ horizon (Table 1). However, values for $w$ calculated from the CT images for stepwise, smaller voxels vary markedly throughout the reference cube with an increased resolution up to a 1-mm voxel size edge length (Fig. 12 and 13, Table 4). Gravimetric water content varies between 0 and $5.57 \mathrm{~g} \mathrm{~g}^{-1}$ for the $\mathrm{Ck}_{1}$ horizon and between 0 and $0.8 \mathrm{~g} \mathrm{~g}^{-1}$ for the $\mathrm{Ck}_{2}$ horizon. For increased resolution up to a pixel size of $0.25 \mathrm{~mm}$, we cannot expect a significant increase in the range of water content that corresponds to a frequency distribution of relative water volume WV (see Fig. 9).

In comparison, we find a more heterogeneous relative frequency distribution of soil water content within the $\mathrm{Ck}_{1}$ horizon (Fig. 12). These results illustrate that it is incorrect to assume that a uniform water content distribution at the microscale level exists throughout the entire soil sample.

\section{Heterogeneity of Soil Bulk Density at the Microscale}

Independently of the differentiation in narrow-spaced heterogeneity of soil structure between both $\mathrm{Ck}$ horizons, stepwise subdivision of the reference cube into pixels leads to a continuously wider range of dry bulk density values for both horizons up to a 1-mm voxel size (Fig. 13 and 14, Table 4). Dry bulk density varies between 0 and $1.87 \mathrm{~g} \mathrm{~cm}^{-3}$ for the $\mathrm{Ck}_{1}$ horizon and between 0 and $1.96 \mathrm{~g} \mathrm{~cm}^{-3}$ for the $\mathrm{Ck}_{2}$ horizon. With a further increase in resolution, we can ignore the changes in the differentiation of bulk density. The results correspond in tendency to the frequency distribution of the relative solid volume (Fig. 11).

The differences between values of dry bulk density calculated using a unique water content estimated in the field and those calculated for specific water contents by means of dual energy scanning are significant and should not be ignored (Fig. 15). The error ranges from $-33 \%$ to $38 \%$ for voxels with $2-\mathrm{mm}$ edge length with an underestimation of the density of higher density regions and an overestimation of the lower density regions. For voxel sizes $<2$-mm edge length, these deviations are even more distinctive.

\section{Heterogeneity of Water Content and Dry Bulk Density Relations}

For low resolution, the gravimetric water content appeared to be inversely related to bulk density. However, for high resolution, a clear relationship between gravimetric water content and bulk density could not be identified (Fig. 13). There are a large number of volume elements comprised of only solid and water, or solid and air phases, for both horizons at the 1-mm voxel edge length resolution. Voxels with only solid and water phases occur in the dry bulk density range from 0.49 to $1.50 \mathrm{~g} \mathrm{~cm}^{-3}$ for the $\mathrm{Ck}_{1}$ horizon and from 0.63 to 1.61 $\mathrm{g} \mathrm{cm}^{-3}$ for the $\mathrm{Ck}_{2}$ horizon, whereas voxels comprising solid and air phases occur predominantly in the wider dry bulk density range, 0.01 to $1.87 \mathrm{~g} \mathrm{~cm}^{-3}$ for $\mathrm{Ck}_{1}$ horizon and 0.13 to $1.96 \mathrm{~g} \mathrm{~cm}^{-3}$ for $\mathrm{Ck}_{2}$ horizon. As expected, the drier and more dense core from the $\mathrm{Ck}_{1}$ horizon is characterized by a greater number of voxels with completely air-filled pores and a lower number of 


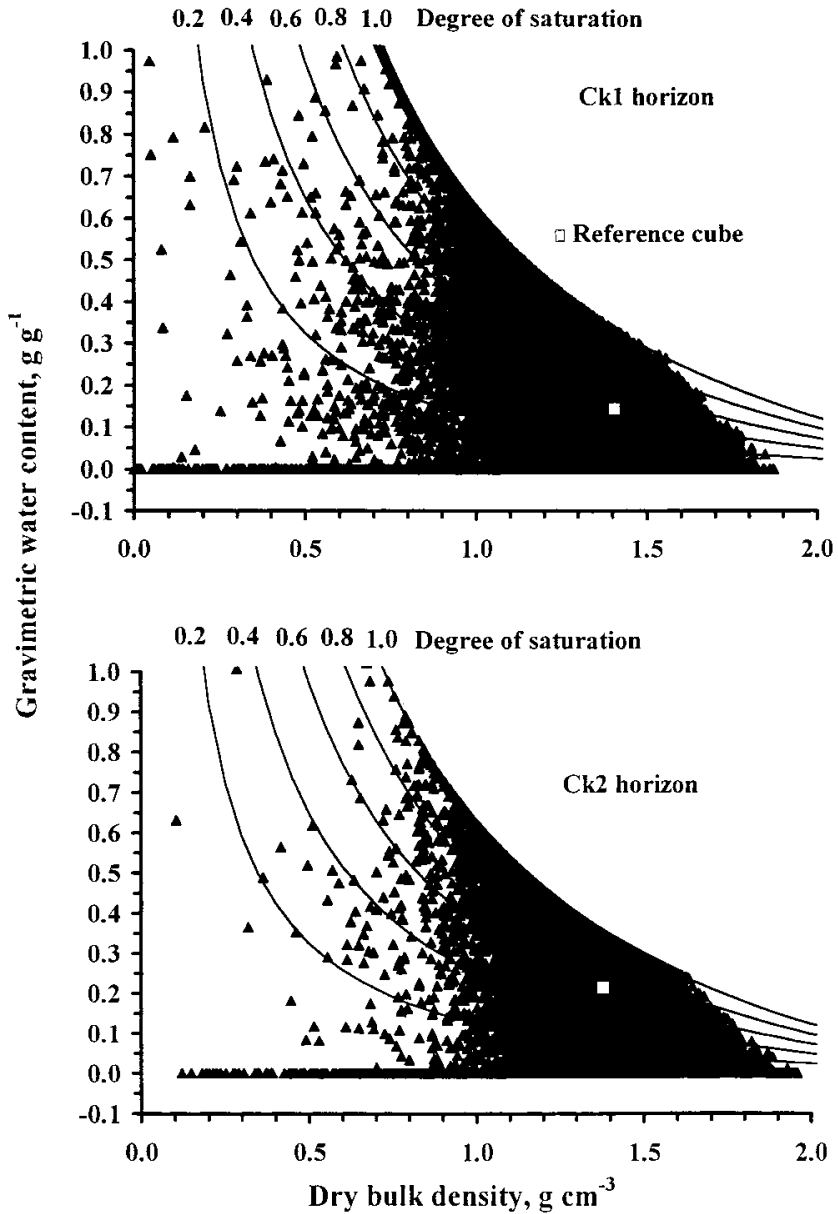

Fig. 13. Gravimetric water content vs. dry bulk density for voxels with 1-mm edge length from cores of $\mathrm{Ck}_{1}$ and $\mathrm{Ck}_{2}$ horizons in comparison to reference cube.

voxels with completely water-filled pores. Moreover, the more heterogeneous core from the $\mathrm{Ck}_{1}$ horizon manifests a larger area relating water content vs. dry bulk density (Fig. 13). The weighted mean of the derived gravimetric water contents and dry bulk densities agrees with the sample's water content and the dry bulk density obtained by weighing (Table 4).

\section{Error Analysis}

The obtained results are influenced by the uncertainty that results from using a CT scanner measuring system:
- The noise of computer assisted tomography (CAT) systems was investigated using a water phantom. At energy levels of $80 \mathrm{kV}$ and $120 \mathrm{kV}$ we had to consider a variation in the range of \pm 4 HUs for the Siemens Somatom Plus scanner.

- For homogeneity tests with a water phantom, the influence of the position of the subunits considered for measured HUs was investigated. Here the difference between HUs of defined regions of interest in the center of the water phantom and those at its periphery demonstrates a variation within the range of \pm 4 HUs.

The error analysis was conducted based on a deviation of \pm 8 HUs. The HUs of the pure soil phases, $\mathrm{HU}_{\text {matrix }}$, $\mathrm{HU}_{\text {water }}$, and $\mathrm{HU}_{\text {air }}$, were considered as fixed according to Phogat et al. (1991). We calculated for the parameters $\mathrm{SV}, \mathrm{WV}, \mathrm{AV}$, and $\rho_{\mathrm{b}}$ a variation of $\pm 0.015 \mathrm{~cm}^{3} \mathrm{~cm}^{-3}$, $\pm 0.008 \mathrm{~cm}^{3} \mathrm{~cm}^{-3}, \pm 0.008 \mathrm{~cm}^{3} \mathrm{~cm}^{-3}$, and $\pm 0.039 \mathrm{~g} \mathrm{~cm}^{-3}$, respectively, for the specific subunit phase composition of the soil core sample.

\section{Variation Caused by Dual Energy-level Scanning}

During the dual energy-level scanning procedure, we scanned at every desk position alternately at $80 \mathrm{kV}$ and $120 \mathrm{kV}$. Thus, we could prevent variations in HUs and calculated soil physical parameters that occur when the scanner desk-positioning precision during the scanning procedure is lost because of repeated forward or backward movement.

\section{Replicates in Investigating Soil Core Samples}

The experiments per core were not replicated, due to the problems with precision in scanner desk positioning. Other cores were not investigated intensively because of the high labor, time, and cost requirements for the experiments. However, dual energy-level scanning demonstrated the general suitability for also calculating soil physical parameters in connection with calibration measurements for estimating the $\mathrm{HU}_{\text {matrix }}$ values of soil core samples.

\section{Standard Deviation of Parameters of Voxels or Pixels Within the Reference Cube}

As a result of the step-by-step division of the so-called reference cube into smaller volume elements down to the pixel size, the subunits became more and more ho-

Table 4. Mean and standard deviation of the gravimetric water content, $w$, and of the dry bulk density, $\rho_{b}$, for the soil samples of $\mathrm{Ck}_{1}$ and $\mathrm{Ck}_{2}$ horizons and for different voxel edge lengths.

\begin{tabular}{|c|c|c|c|c|c|c|c|c|c|c|c|}
\hline \multirow[b]{3}{*}{ Horizon } & \multirow{3}{*}{$\begin{array}{l}\text { Para- } \\
\text { meter }\end{array}$} & \multirow{3}{*}{$\begin{array}{l}\text { Core } \dagger \\
\text { Mean }\end{array}$} & \multicolumn{9}{|c|}{ Edge length of voxels } \\
\hline & & & \multirow{2}{*}{$\frac{70 \mathrm{~mm}+}{\text { Mean }}$} & \multicolumn{2}{|c|}{$10 \mathrm{~mm}$} & \multicolumn{2}{|c|}{$5 \mathrm{~mm}$} & \multicolumn{2}{|c|}{$2 \mathrm{~mm}$} & \multicolumn{2}{|c|}{$1 \mathrm{~mm}$} \\
\hline & & & & Mean & SD & Mean & SD & Mean & SD & Mean & SD \\
\hline $\begin{array}{l}\mathbf{C k}_{1} \\
\mathbf{C k}_{2}\end{array}$ & $\begin{array}{l}w \\
w\end{array}$ & $\begin{array}{l}0.152 \\
0.223\end{array}$ & $\begin{array}{l}0.147 \\
0.215\end{array}$ & $\begin{array}{l}\mathbf{0 . 1 5 0} \\
\mathbf{0 . 2 1 4}\end{array}$ & $\begin{array}{l}0.027 \\
0.021\end{array}$ & $\begin{array}{l}0.151 \\
0.214\end{array}$ & $\begin{array}{l}0.038 \\
0.036\end{array}$ & $\begin{array}{l}0.151 \\
0.218\end{array}$ & $\begin{array}{l}0.084 \\
0.093\end{array}$ & $\begin{array}{l}0.150 \\
0.223\end{array}$ & $\begin{array}{l}0.177 \\
0.143\end{array}$ \\
\hline & & & & & & $-\mathbf{g}$ & & & & & \\
\hline $\mathbf{C k}_{1}$ & $\rho_{\mathrm{b}}$ & 1.412 & 1.404 & 1.401 & 0.058 & 1.401 & 0.078 & 1.400 & 0.119 & 1.397 & 0.180 \\
\hline $\mathbf{C k}_{2}$ & $\rho_{\mathrm{b}}$ & 1.380 & 1.379 & 1.380 & 0.046 & 1.380 & 0.059 & 1.381 & 0.103 & 1.380 & 0.147 \\
\hline
\end{tabular}

$\dagger$ Measured for the bulk sample, based on weighing.

$\ddagger$ Reference cube. 

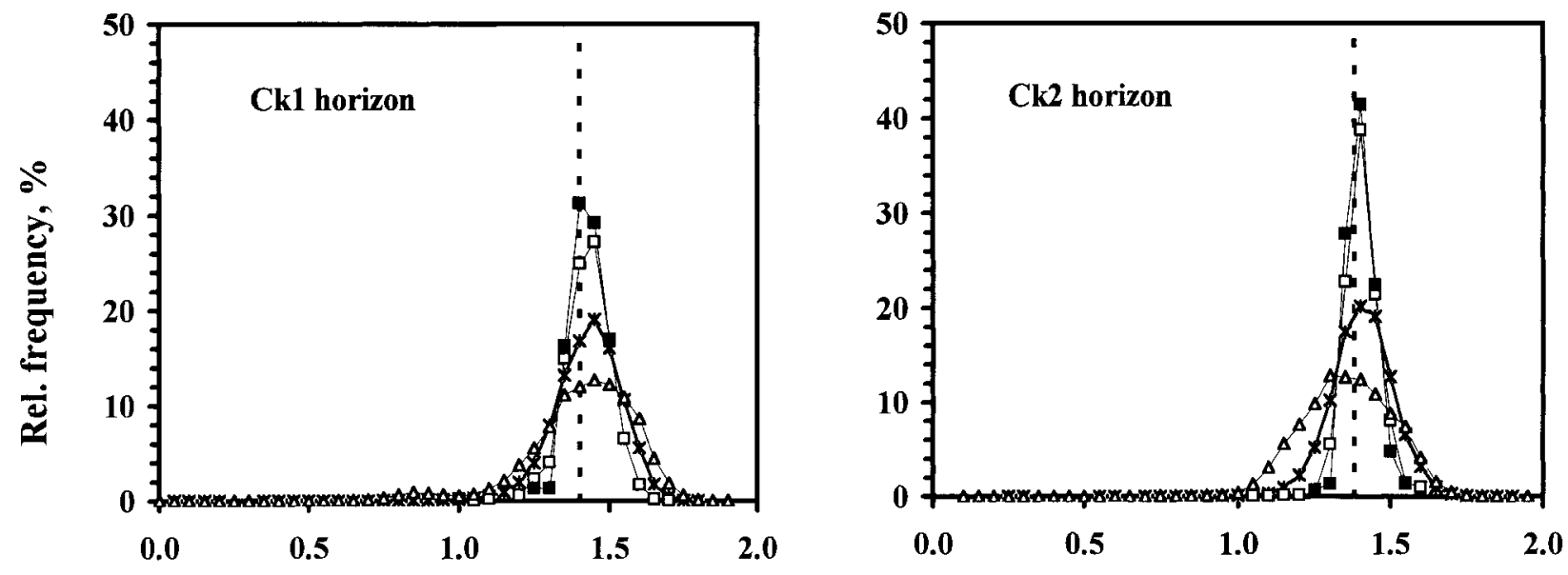

Dry bulk density, $\mathrm{g} \mathrm{cm}^{-3}$

Voxel edge length

$\triangle 1 \mathrm{~mm} \rightarrow-2 \mathrm{~mm} \rightarrow 5 \mathrm{~mm} \longrightarrow 10 \mathrm{~mm}-\cdot$ mean

Fig. 14. Frequency of dry bulk density classes for various voxel edge lengths in the cores of $\mathrm{Ck}_{1}$ and $\mathrm{Ck}_{2}$ horizons.

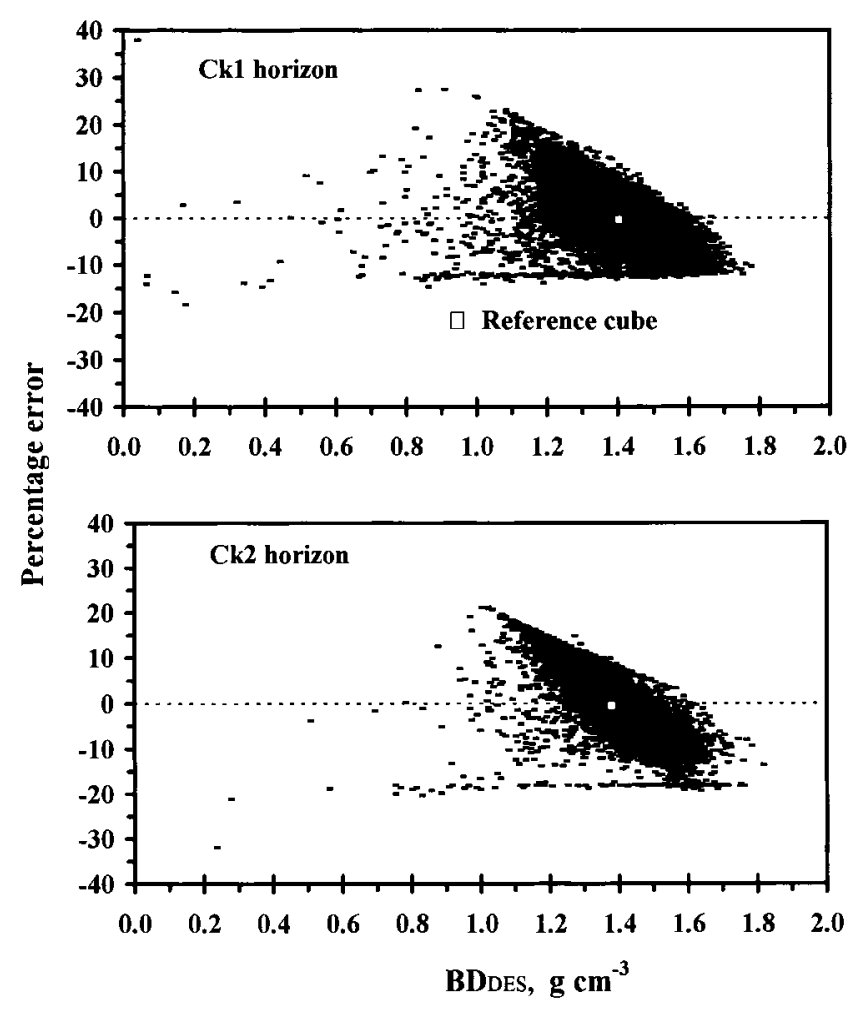

Fig. 15. Percentage error in soil bulk density determination by assuming unique water content vs. calculated soil bulk density from dual energy scanning (BDDES) for voxels with 2-mm edge length from cores of $\mathbf{C k}_{1}$ and $\mathrm{Ck}_{2}$ horizons in comparison to reference cube.

$$
\text { Percentage error }=\frac{\text { BDG }- \text { BDDES }}{\text { BDG }}
$$

$\dagger$ BDG, soil bulk density determined gravimetrically. mogeneous and the standard deviation of parameters of the subunits increased (Table 3 and 4, Fig. 3).

\section{CONCLUSION}

The primary objective of our use of dual energy-level CT scanning was to reveal heterogeneity of water content, dry bulk density, and multi-phase composition in soil samples based on a calculation of these parameters for volume elements with different edge lengths. The results suggest that dual energy-level scanning can be used to estimate the variation of multi-phase composition, water content, and dry bulk density at the investigated resolutions.

Based on these results it will be possible to investigate the spatial distribution of the investigated parameters within soil core samples and to identify (i) macropores in their continuity and connectivity, as well as (ii) zones of lower bulk density and preferential flow paths.

For the investigated silt loam a resolution with a voxel size of 1-mm edge length was sufficient; higher resolutions provided no more additional information. But these results cannot be generalized. Normally, the necessary resolution depends on the corresponding soil structure at the microscale level. As a consequence of high resolution soil structure investigations at the $\mathrm{mm}$ or $\mu \mathrm{m}$-scale, we have to investigate the influence of the variation in particle-size distribution on the measured HU values. It is possible that the detected narrowspaced heterogeneity is the result of a narrow-spaced differentiation in particle-size distribution as well. With the development of increasing resolution scanning systems, the limitations for its use appear. The higher the resolution used, the smaller is the size of the investigated core with respect to time consumption, labor intensity, and handling of data sets. Existing CAT scanning sys- 
tems with resolutions of 2 to $10 \mu \mathrm{m}$ (Spanne et al., 1994) are then suitable for special investigations such as a measurement of (i) macropore wall roughness, (ii) density distribution within aggregates, (iii) intersphere between soil and roots, and (iv) construction of roots.

\section{ACKNOWLEDGMENTS}

The authors wish to thank Mrs. Ingrid Onasch for field and laboratory help and statistical investigations, Dr. Arne-Jörn Lemke and Mrs. Judith Döring for x-ray computed tomography measurements in the Virchow hospital in Berlin, and Dr. Karin Kotzke for computational and statistical investigations. The helpful comments of Dr. Donald R. Nielsen, Davis, CA, are gratefully acknowledged. We thank Sarah Ellgen for her help with the English language.

This collaboration was enabled by the British Council and the German Academic Exchange Service (DAAD), under the Anglo-German ARC Project 500 Scheme. We also acknowledge the Scottish Office Agriculture, Environment and Fisheries Department for grant-in-aid.

\section{REFERENCES}

Anderson, S.H., and C.J. Gantzer. 1987. Determination of soil water content by $\mathrm{x}$-ray computed tomography and NMR imaging. p. 239-245. In R.J. Hanks and R.W. Brown (ed.) Proc. Int. Conf. on Measurement of Soil and Plant Water Status. Utah State Univ., Logan, UT.

Anderson, S.H., C.J. Gantzer, J.M. Boone, and R.J. Tully. 1988. Rapid nondestructive bulk density and soil water content determination by computed tomography. Soil Sci. Soc. Am. J. 52:35-40.

Anderson, S.H., and C.J. Gantzer. 1989. Determination of soil water content by x-ray computed tomography and magnetic resonance imaging. Irrig. Sci. 10:63-71.

Anderson, S.H., R.L. Peyton, and C.J. Gantzer. 1990. Evaluation of constructed and natural soil macropores using x-ray computed tomography. Geoderma 46:13-29.

Brown, J.M., W.C. Fonteno, D.K. Cassel, and G.A. Johnson. 1987. Computed tomographic analyses of water distribution in three porous foam media. Soil Sci. Soc. Am. J. 51:1121-1125.

Chen, May-Ru, R.E. Hinkley, and J.E. Killough. 1996. Computed tomography imaging of air sparging in porous media. Water Resour. Res. 32:3013-3024.

Crestana, S., S. Mascarenhas, and R.S. Pozzi-Mucelli. 1985. Static and dynamic three-dimensional studies of water in soil using computed tomography scanning. Soil Sci. 140:326-332.

Crestana, S., R. Cesareo, and S. Mascarenhas. 1986. Using a computed tomography miniscanner in soil science. Soil Sci. 142:56-61.

Cruvinel, P.E., R. Cesareo, S. Crestana, and S. Mascarenhas. 1990. Xand $\gamma$-rays computerized minitomograph scanner for soil science. IEEE Trans. on Instrumentation and Measurement 39:745-750.

DiCarlo, D.A., T.W.J. Bauters, T.S. Steenhuis, J.-Y. Parlange, and B.R. Bierck. 1997. High-speed measurements of three-phase flow using synchroton X rays. Water Resour. Res. 33:569-576.

Grevers, M.C.J., E. de Jong, and R.J. St. Arnaud. 1989. The characterization of soil macroporosity with CT scanning. Can. J. Soil Sci. 69:629-637.

Grevers, M.C.J., and E. de Jong. 1994. Evaluation of soil pore continuity using geostatistical analysis on macroporosity in serial sections obtained by computed tomography scanning. p. 73-86. In S.H. Anderson and J.W. Hopmans (ed.) Tomography of soil-water-root processes. SSSA Spec. Publ. 36. SSSA, Madison, WI.

Grose, M.J., C.A. Gilligan, D. Spencer, and B.V.D. Goddard. 1996.
Spatial heterogeneity of soil water around single roots: Use of CT-scanning to predict fungal growth in the rhizosphere. New Phytol. 133:261-272.

Hainsworth, J.M., and L.A.G. Aylmore. 1983. The use of computer assisted tomography to determine spatial distribution of soil water content. Aust. J. Soil Res. 21:435-443.

Hainsworth, J.M., and L.A.G. Aylmore. 1986. Water extraction by single plant roots. Soil Sci. Soc. Am. J. 50:841-848.

Heijs, A.W.J., J. de Lange, J.F.Th. Schoute, and J. Bouma. 1995. Computed tomography as a tool for non-destructive analysis of flow patterns in macroporous clay soils. Geoderma 64:183-196.

Heijs, A.W.J., C.J. Ritsema, and L.W. Dekker. 1996. Three-dimensional visualization of preferential flow patterns in two soils. Geoderma 70:101-116.

Hopmans, J.W., T. Vogel, and P.D. Koblik. 1992. X-ray tomography of soil water distribution in one-step outflow experiments. Soil Sci. Soc. Am. J. 56:355-362.

Hopmans, J.W., M. Cislerova, and T. Vogel. 1994. X-ray tomography of soil properties. p.17-28. In S.H. Anderson and J.W. Hopmans (ed.) Tomography of soil-water-root processes. SSSA Spec. Publ. 36. SSSA, Madison, WI.

Jenssen, P.D., and P.H. Heyerdahl. 1988. Soil column descriptions from $\mathrm{x}$-ray computed tomography density images. Soil Sci. 146: 102-107.

Petrovic, A.M., J.E. Siebert, and P.E. Rieke. 1982. Soil bulk density analysis in three dimensions by computed tomographic scanning. Soil Sci. Soc. Am. J. 46:445-450.

Peyton, R.L., B.A. Haeffner, S.H. Anderson, and C.J. Gantzer. 1992. Applying X-ray CT to measure macropore diameters in undisturbed soil cores. Geoderma 53:329-340.

Peyton, R.L. C.J. Gantzer, S.H. Anderson, B.A. Haeffner, and P. Pfeiffer. 1994. Fractal dimension to describe soil macropore structure using x-ray computed tomography. Water Resour. Res. 30: 691-700.

Phogat, V.K., and L.A.G. Aylmore. 1989. Evaluation of soil structure by using computer assisted tomography. Aust. J. Soil Res. 27: 313-323.

Phogat, V.K., L.A.G. Aylmore, and R.D. Schuller. 1991. Simultaneous measurement of the spatial distribution of soil water content and bulk density. Soil Sci. Soc. Am. J. 55:908-915.

Rogasik, H., L. Müller, and J. Brunotte. 1994. Using x-ray computed tomography for studying soil structural heterogeneity. p. 549-554 In H.E. Jensen, P. Schjonning, and S.A. Mikkelsen (ed.) Proc. 13th Int. Soil \& Tillage Res. Org. Conf. "Soil Tillage for Crop Production and Protection of the Environment," Aalborg, Denmark. 24-29 July 1994. The Royal Veterinary and Agric. Univ. and the Danish Inst. of Plant and Soil Sci., Aalborg, Denmark.

Soil Survey Staff. 1975. Soil taxonomy: A basic system of soil classification for making and interpreting soil surveys. USDA-SCS Agric. Handb. 436. U.S. Gov. Print. Office, Washington, DC.

Spanne, P., K.W. Jones, L. Prunty, and S.H. Anderson. 1994. Potential applications of synchrotron computed microtomography to soil science. p. 43-57. In S.H. Anderson and J.W. Hopmans (ed.) Tomography of soil-water-root processes. SSSA Spec. Publ. 36 SSSA, Madison, WI.

Tollner, E.W., and L.E. Ramseur. 1988. Using computed tomography to measure soil moisture and bulk density in the presence of a growing plant. Int. Winter Meeting of the ASAE. Paper 88-1625.

Tollner, E.W., and B.P. Verma. 1989. X-ray CT for quantifying water content at points within a soil body. Trans. ASAE 32:901-905.

Vaz, C.M.P., S. Crestana, S. Mascarenhas, P.E. Cruvinel, K. Reichardt, and R. Stolf. 1989. Using a computed tomography miniscanner for studying tillage induced soil compaction. Soil Technol. 2:313-321.

Warner, G.S., J.L. Nieber, I.D. Moore, and R.A. Geise. 1989. Characterizing macropores in soil by computed tomography. Soil Sci. Soc. Am. J. 53:653-660.

Wegener, O.H. 1992. Ganzkörpercomputertomographie. 2 Auflage. Blackwell Wissenschaft, Berlin. 